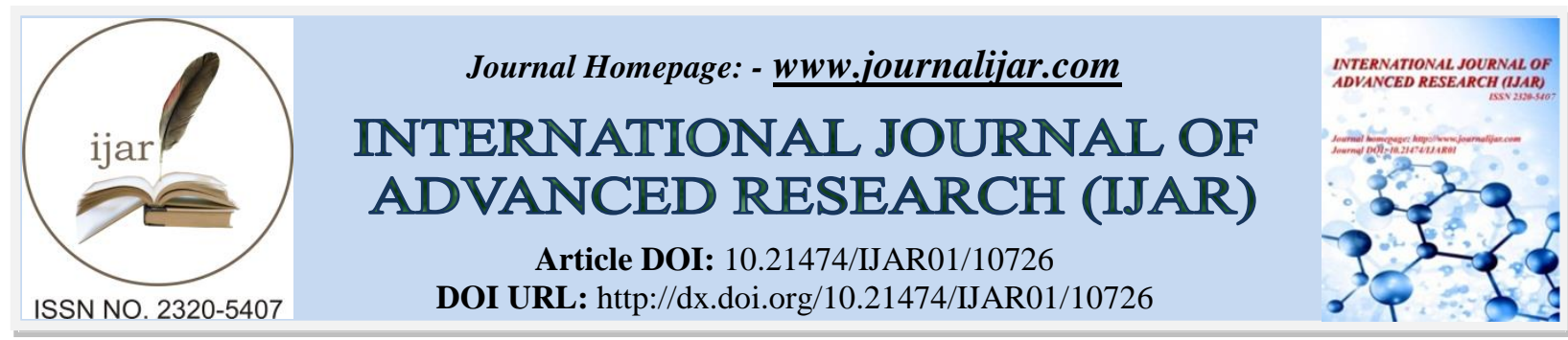

RESEARCH ARTICLE

\title{
PREDICTION OF THE YOUNG MODULUS OF THE EARTH REINFORCED BY THE STRAW
}

\section{Christian Enagnon Adadja ${ }^{2}$, Clément Adéoumi Labintan ${ }^{2}$, Mohamed Gibigaye ${ }^{2}$, Hamid Zahrouni ${ }^{1}$, Mahdia Hattab $^{1}$ and Mohamad Jrad ${ }^{1}$}

1. Laboratory of Microstructure Studies and Mechanics of Materials (LEM3), University of Lorraine, Metz, France.

2. Laboratory of Applied Energetics and Mechanics (LEMA), Polytechnic School of Abomey-Calavi / University of Abomey-Calavi, Cotonou (Benin).

\section{Manuscript Info}

\section{Manuscript History}

Received: 25 January 2020

Final Accepted: 27 February 2020

Published: March 2020

Key words:-

Digimat, Homogenization, Young's

Modulus, Volume Fraction,

Heterogeneous Materials

\begin{abstract}
Optimization and precise knowledge of the effective properties of heterogeneous materials requires the use of predictive homogenization techniques. The aim of this work is to test numerical models of homogenization with a view to predicting the elastic properties of the clay-rice straw composite. Experimental values from the literature have been compared to that from the digital models Digimat MF and Digimat FE. Note that the Digimat MF semi-analytical model gives values closer to the experimental ones. This is confirmed by the reliability study of the two models which was carried out. Indeed, up to a volume fraction value of $25 \%$, the ratio of the values predicted by the MF model to the experimental ones are closer to unity than those obtained by the FE model. We then deduce that the MF model is more reliable in predicting the elastic moduli of the rice straw clay composite. It was also highlighted the decrease in Young's modulus as a function of the increase in the volume fraction of rice straws. This remark is made on all models.
\end{abstract}

Copy Right, IJAR, 2020,. All rights reserved.

\section{Introduction:}

Predicting the mechanical properties of composites with plant inclusions constitutes a new field of research. Previous work on the mechanical behaviour of the composite associating rice straw with clay soil has mainly focused on the study of its formulation, density, time and ripening conditions. The majority of these studies relate to experimental aspects, which have proven to be tedious and expensive and do not allow a clear idea of the optimal performance of the material. Few studies have focused on predicting the behaviour of the clay-rice straw composite. Theoretical approaches are therefore rarer. This study focuses on the use of digital homogenization methods used to best estimate the properties of this type of material.

Indeed, homogenization is a modelling technique which assimilates a heterogeneous material to an equivalent fictitious homogeneous material, whose characteristics must be determined [1], [2]. Since the clay-rice straw composite is a heterogeneous material, its mechanical behaviour depends on its constituents, on the mechanisms at the interfaces, but also on the adhesion of its constituents.

Corresponding Author: Christian Enagnon Adadja

Address: Laboratory of Applied Energetics and Mechanics (LEMA), Polytechnic School of Abomey-

Calavi / University of Abomey-Calavi, 01 BP. 2009 Cotonou (Benin). 
To predict its behaviour or optimize these mechanical characteristics, scaling models that take into account the characteristics of the microstructure are the most suitable.

It is now more and more illusory to wish to model a composite material using an exclusively macroscopic approach and this for two essential reasons. The first is that this type of approach masks physical phenomena and does not know how to discern the true causes of phenomena observed on a macroscopic scale. The second reason is that the power of computers now makes it possible to solve problems of homogenization and to digitally process multiscale processes [3]. Thus taking into account fine and complex phenomena turns out to be entirely feasible and homogenization becomes an effective tool for analysing the behaviour of composite materials [4].

The main objective is to use a fast, reliable and efficient tool as a material performance simulator. The prediction from the numerical models will be compared with experimental measurements from the literature for volume fractions of rice straw up to $40 \%$. The proposed multi-scale modelling has been limited only to the estimation in linear elasticity for variable formulations.

\section{Numerical Homogenization Method:}

Predicting the properties of composite materials taking into account the macroscopic and microscopic scale requires the preparation of a clean code in most cases. But with the evolution of work in this area certain programs are also able to carry out this operation [5]. Numerical methods of homogenization are numerous and we can cite the one based on a direct analysis by finite elements or the one based on the mean field.

This study is carried out in this work using the Digimat software which offers the opportunity to test these two techniques.

\section{Multiscale modelling assumptions:}

The calculation of the effective properties of the materials is made according to certain assumptions which are:

1. the microstructural parameters are known

2. the mechanical characteristics of the two phases of the composite are known

3. both phases have ideal grip

The elastic properties of the two phases are presented in the following table:

Table 1:- Characteristics of the different phases of the composite.

\begin{tabular}{|l|l|l|}
\hline Phases & Young's modulus, E (MPa) & Poisson's ratio, v \\
\hline Clay Matrix & $175[6]$ & $0.3[7]$ \\
\hline Fibers & $17[8]$ & $0.3[9]$ \\
\hline
\end{tabular}

\section{Multiscale modelling of the elasticity module of the composite using the Digimat MF model:}

Digimat MF is a tool for estimating the elastic properties of a composite material. It simulates the behaviour of the elastoplastic behaviour of composite materials using the Huber-Mises-Hencky criterion (HMH). This medium field homogenization technique uses the Mori-Tanaka method. The boundary conditions and the applied deformation are equal to 0.3 (the deformation factor is equal to 0.3 ). The loading is of uniaxial deformation type in direction 1 (Figure 1) 


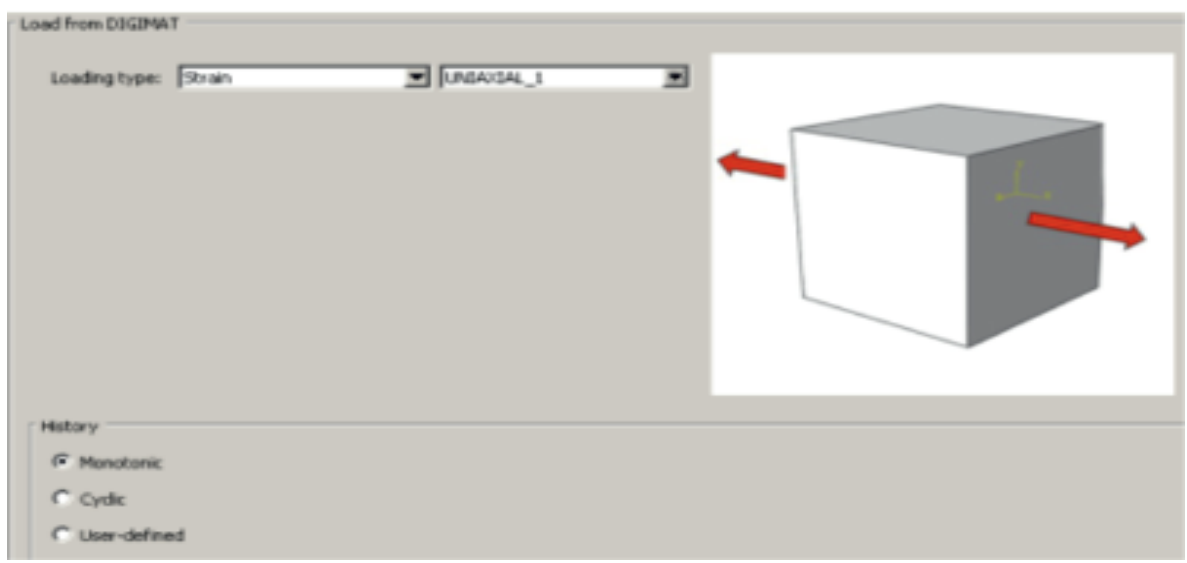

Figure 1: Loading considered in Digimat MF.

After loading, Figure 2 shows an example of stress-strain curve obtained. From this curve, we determine the modulus of elasticity.

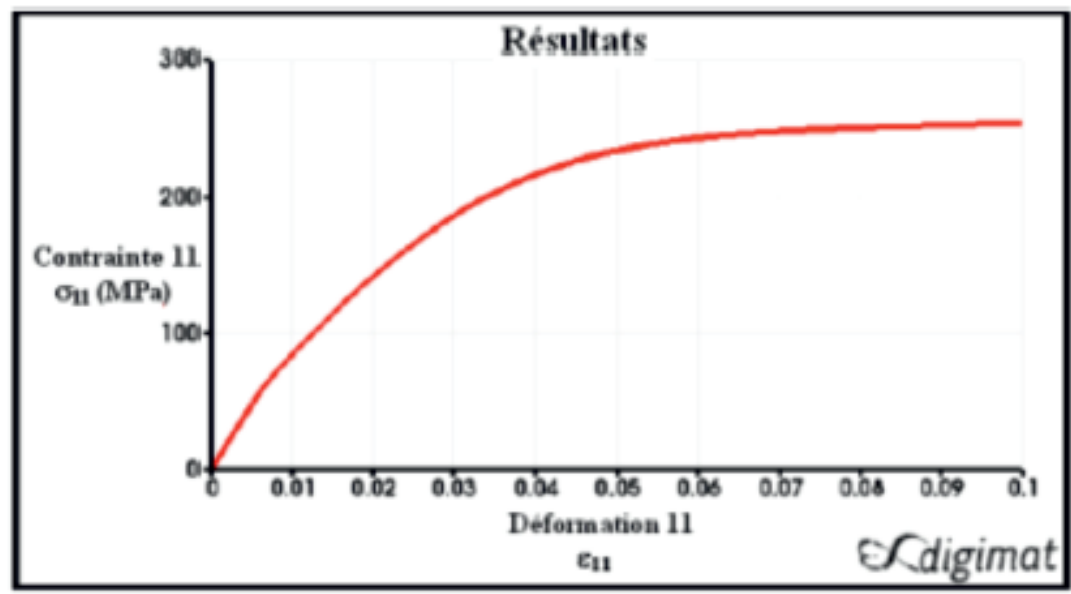

Figure 2: Strain stress curve obtained by the Digimat MF model.

\section{Multiscale modelling of the elasticity module of the composite using the Digimat FE model:}

Digimat FE is a digital homogenization tool that uses the finite element method (FEM). It allows to generate a mesh on a Representative Volume Elementary. This mesh will then be requested with well-defined boundary conditions to calculate the homogenized properties.

We generate Representative Volume Elementary (RVE) for several volume fractions by the Poisson random process used by Digimat FE. The Figure 3 shows the VER generated. 


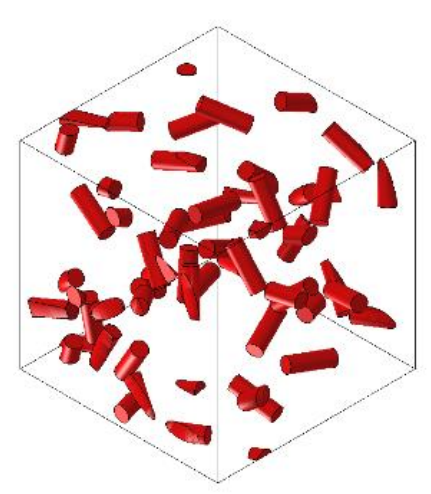

(a) $10 \%$ inclusions

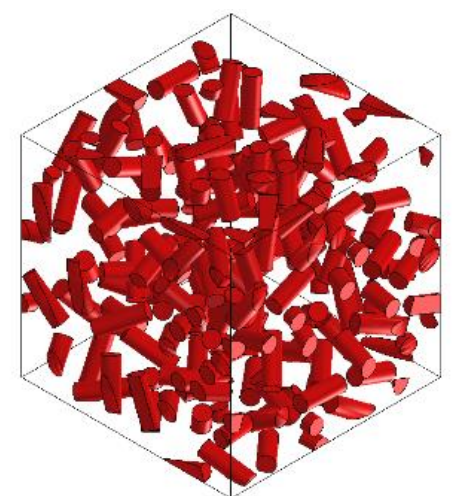

(b) $20 \%$ inclusions

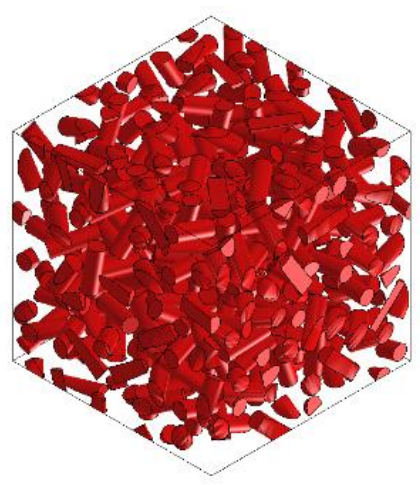

(c) $40 \%$ inclusions

Figure 3: Example of RVE generated by Digimat FE.

After the generation of the RVE, Digimat FE imports this model of RVE into Abaqus CAE to carry out the meshing as shown in the Figure 4. The methodology for creating and meshing a volume of heterogeneous material revolves mainly around three stages as we recalled above: the surface representation of material, the surface mesh and the volume mesh. The mesh used here is that multiphasic which has the advantage of a fast convergence, requires little memory for the machines [10], [11].

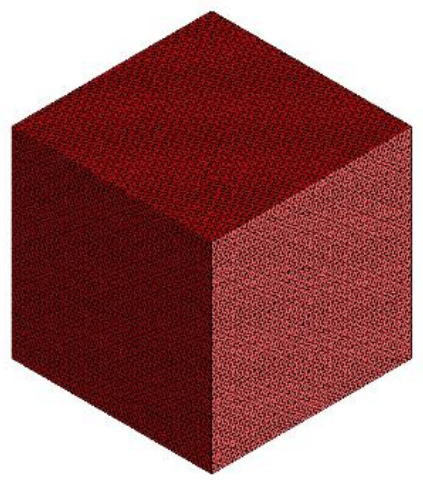

(a) Mesh of the matrix

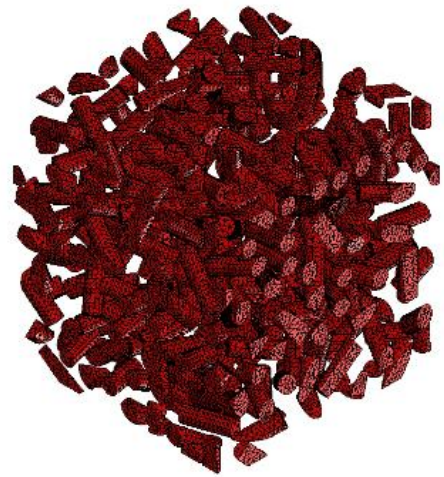

(b) Mesh of the inclusions

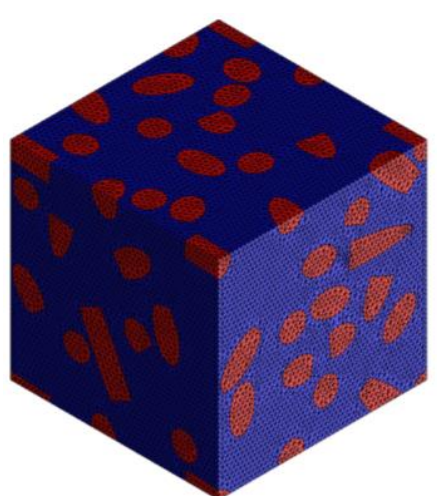

(c) Mesh of the composite

Figure 4: VER mesh for EF analysis with Abaqus CAE.

\section{Convergence of the finite element mesh:}

During the construction of the microstructure, each size of these volumes contains a specific number of inclusions $\mathrm{N}$. Consequently, increasing the size of the volume amounts to increasing the number of inclusions $\mathrm{N}$, while keeping the same volume fraction of the inclusions. For each size N, different realizations $\mathrm{n}$ are considered. We have introduced a limit number $\mathrm{N}$ of 100 inclusions. This choice was made because of the results obtained in other studies which state that with 100 inclusions already one obtains good results for the simulations [12].The study of convergence has shown that it is reached with 350,000 finite elements for a microstructure of 100 inclusions. In the rest of our simulations, we consider this mesh density. 


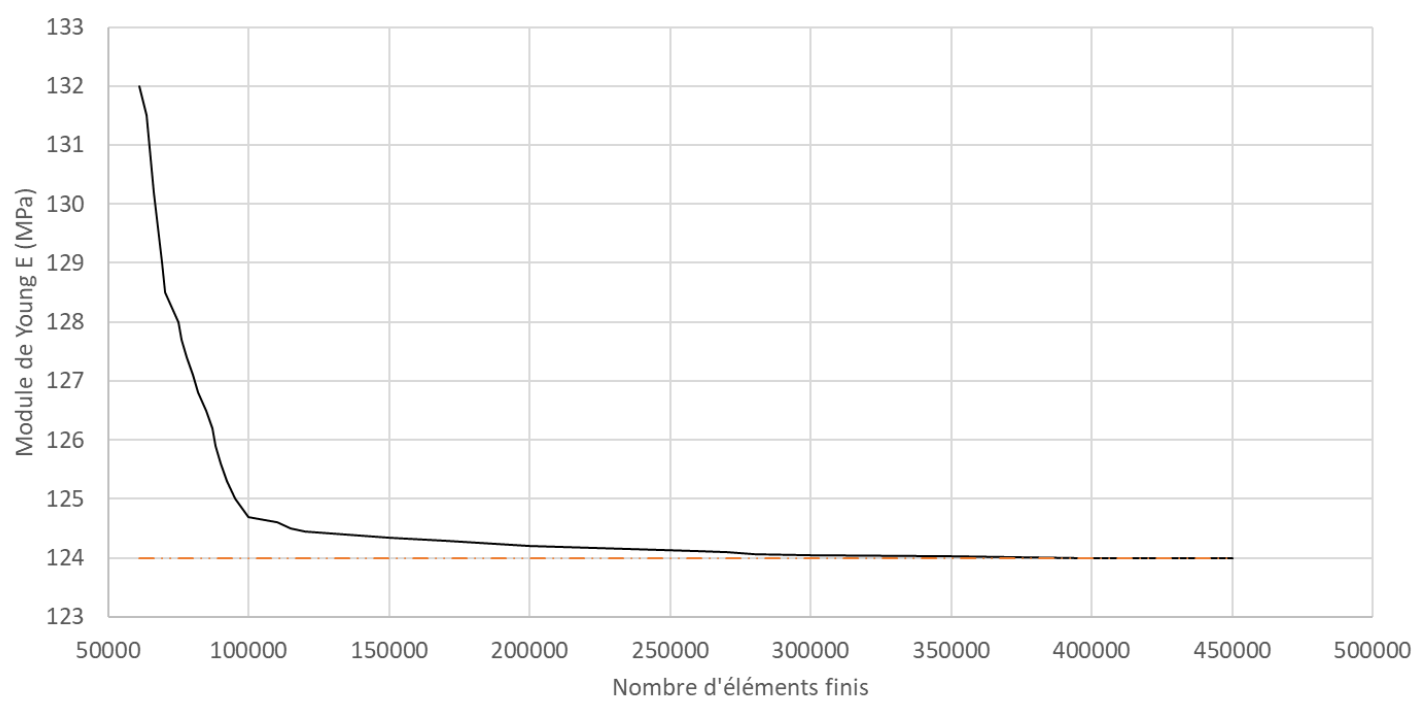

Figure 5: Study of the convergence of the mesh.

\section{Loading the mesh microstructure:}

The loading here is uniaxial (along the axis 1-1). After generation of the mesh, we request our microstructure in axial compression. We post-process the results of the Post processing tasks (FE) analysis using probabilistic distribution functions which give a detailed overview of the requested RVE. The homogenized mean values are calculated and can be used in a subsequent FE analysis on the structural level part. Then the FE module after calculations, (based on the characteristics of each phase) gives the stress and the deformation along each axis of the RVE and consequently it also gives the stress-deformation curve after loading as shown in the Figure 6.

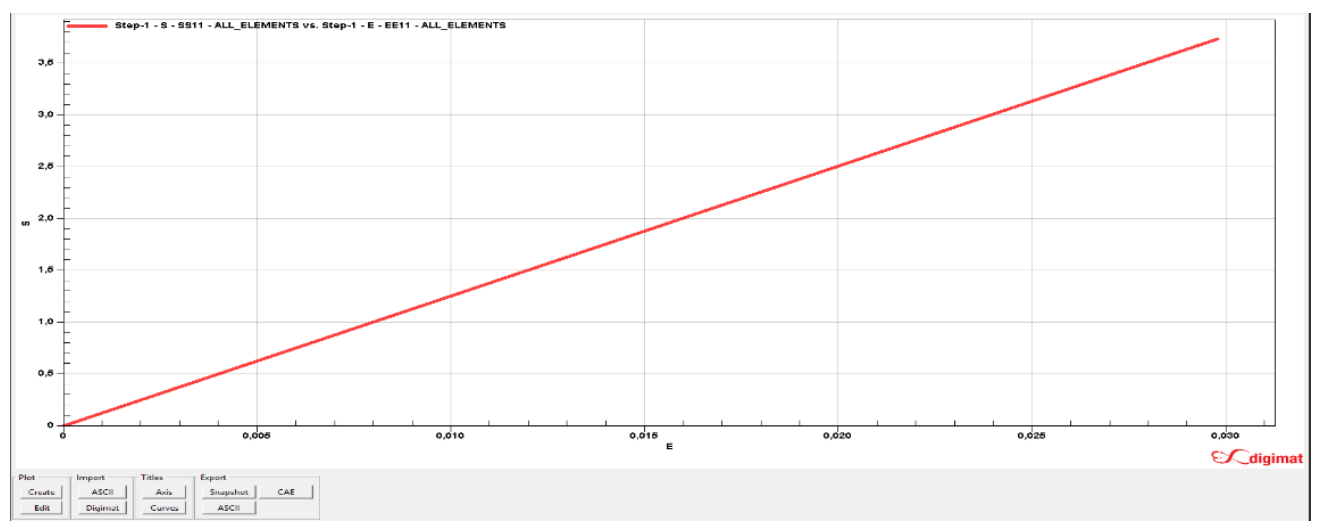

Figure 6: Stress-strain curve given by Digimat FE.

The ratio between the stress along axis 1-1 and the deformation of the axis gives us the value of Young's modulus. As for the value of the fish coefficient, it is the opposite of the ratio between the deformation along the axis 2-2 and the deformation according to $1-1$. 


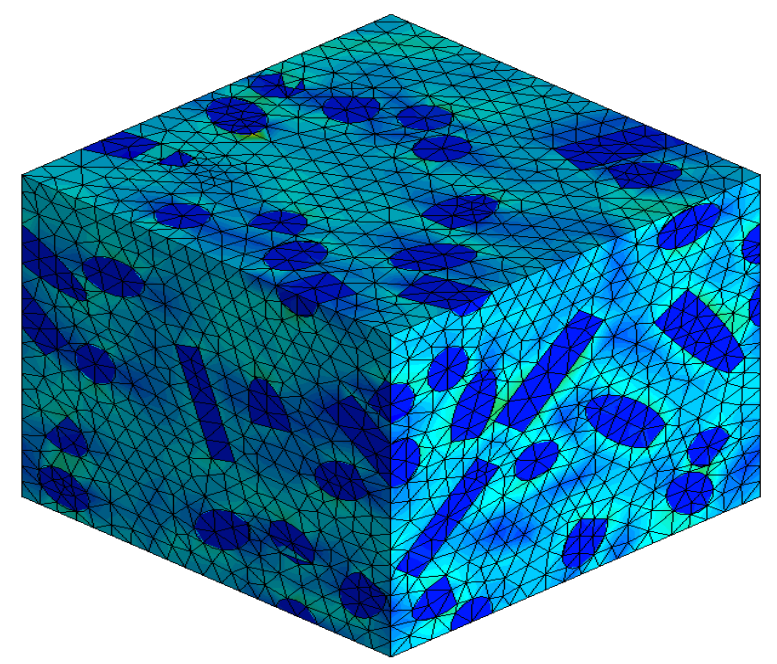

Figure 7: Microstructure obtained after loading.

\section{Results and Discussion:}

In order to validate the results obtained by a reliability study, we made a connection between the experimental values from the literature and the values predicted by the models. The figure 8 shows this report.

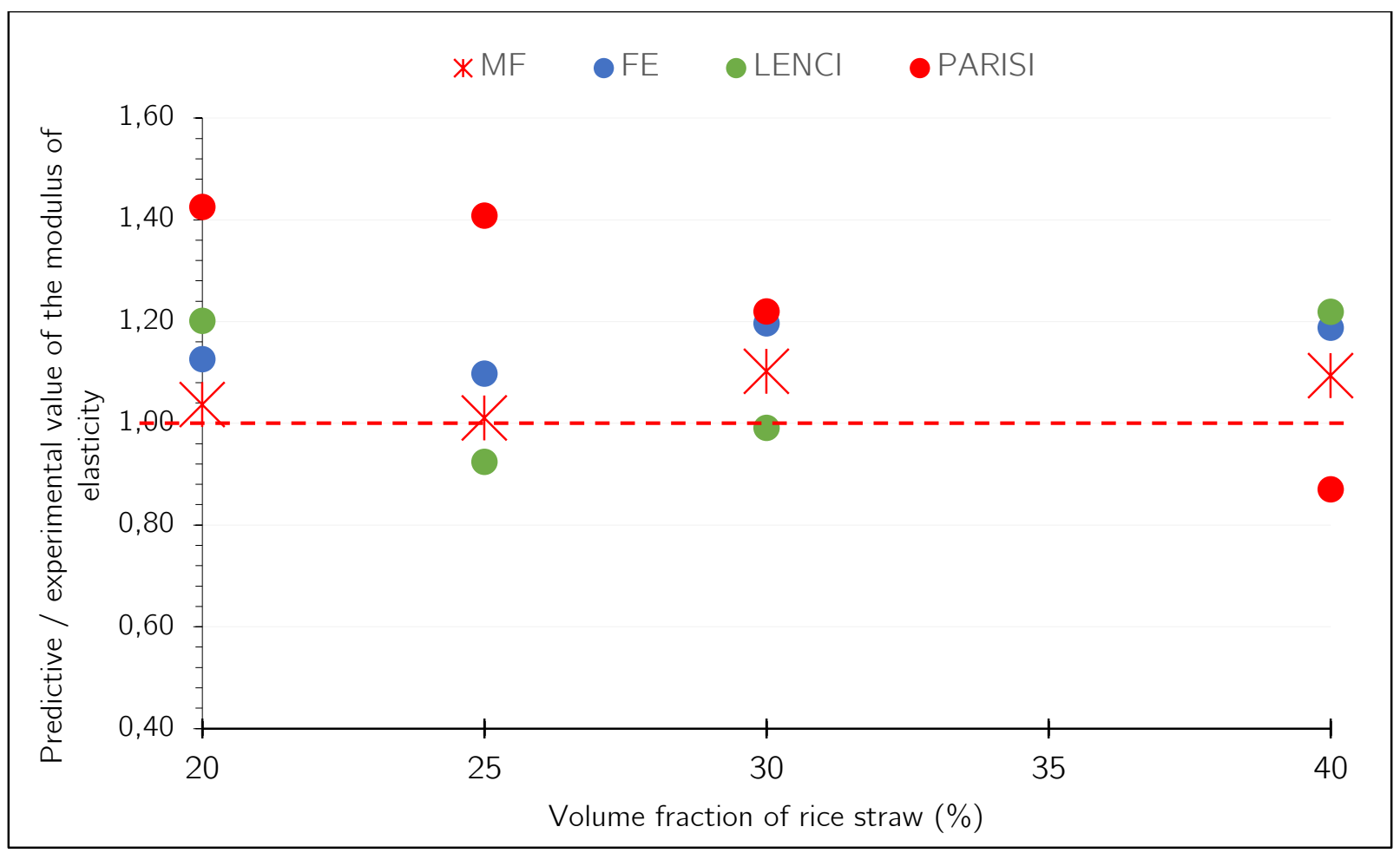

Figure 8: Variation in the ratio of Young's modulus values predicted numerically and experimentally.

We note that the ratios obtained using the predicted values from the semi-analytical model of Digimat MF are closer to unity than those obtained by the finite element model Digimat FE for earth-straw composites with volume fractions not exceeding not 25\%. Beyond this value, the Digimat MF model deviates but is still more reliable than the finite element model. This is explained by the fact that the semi-analytical model takes into account the characteristics of the microstructure. 


\section{Analysis of the variation of Young's modulus:}

An analysis of the variation of the Young's modulus is made, through the curves of the Figure 9 which present the values predicted by the two numerical models used, compared with the experimental values.

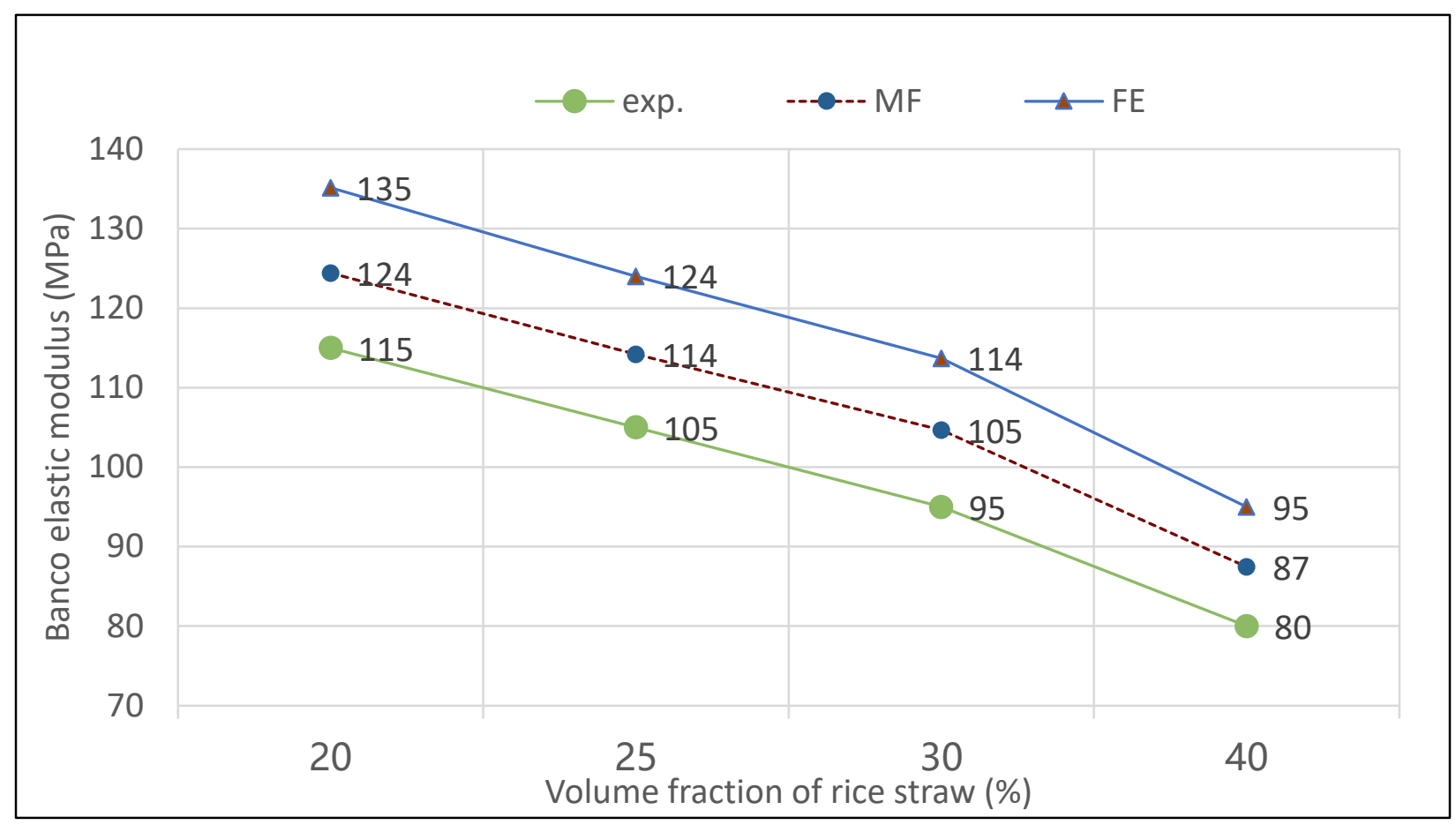

Figure 9: variation of Young's modulus.

A cross analysis of the results shows us that the elastic properties decrease with increasing volume fractions. The Digimat MF model, which is a semi-analytical model derived from the Mori-Tanaka analytical model, gives results that are fairly consistent with the experimental. These results are consistent with Benveniste's analysis [13]. It must be said that numerical models have the merit of giving the actual effective properties of the material by taking into account the characteristics of its different phases.

Using the Digimat MF model we highlight through the Figure 10the variation of Young's modulus of the composite. This tells us better that the decrease in Young's modulus is observed with the increase in the volume fraction of inclusions.

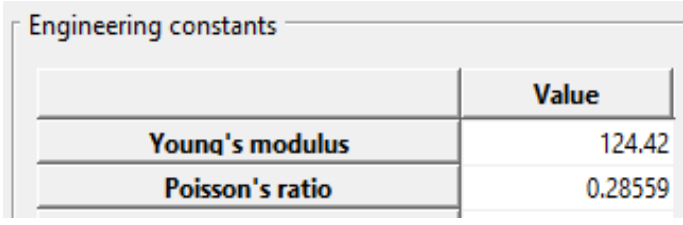

a) Values obtained for $20 \%$ of straws

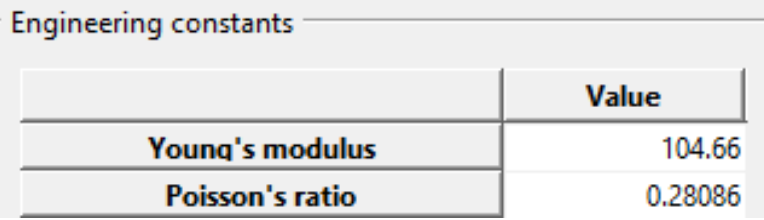

b) Values obtained for $30 \%$ of straws

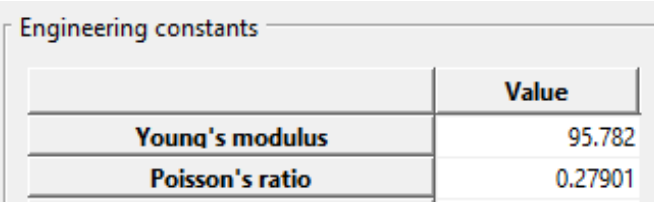

c) Values obtained for $35 \%$ straw

Figure 10:- Variation of elastic properties using Digimat MF. 
This reduction is due to the fact that the rigidity of the straws is much lower (about 10 times less) than that of the clay matrix. This same remark was made by Pham [3] on the lime-hemp composite with volumetric concentrations of hemp between 0 and $33 \%$, and also by Nguyen [14] with resin mortars.

\section{Conclusion:}

In this study, we have estimated the elastic modulus of the clay-rice straw composite using multi-scale approaches. Two digital models Digimat MF and Digimat FE were used.

Overall, the predicted characteristics are close to the experimental values from the literature. But it has been noticed that the Digimat MF model is closer to experimental reality. Numerical models have the merit of taking into account the characteristics of all the components for more precise estimates.

At the end of this study, the results obtained confirm our ambition to popularize the use of this material for modern constructions. This prediction alternative will facilitate engineering calculations for the structural design of buildings.

\section{References:}

[1] M. Bornert, T. Bretheau, et P. Gilormini, Homogénéisation en mécanique des matériaux, Tome 1: Matériaux aléatoires élastiques et milieux périodiques. Hermes science, 2001.

[2] H. Moussaddy, D. Therriault, et M. Lévesque, « Modeling elastic properties of randomly oriented fiber composites », ICCM Int. Conf. Compos. Mater., vol. 2013-July, no 2, p. 4485-4492, 2013.

[3] T.-H. Pham, F. Julien, V. Picandet, et P. Pilvin, «Étude expérimentale, théorique et numérique de l'élasticité de composites chaux-chanvre », 21ème Congrès Français de Mécanique, Bordeaux, p. 1-7, 2013.

[4] T. Trzepieciński, G. Ryzińska, M. Biglar, et M. Gromada, « Modelling of multilayer actuator layers by homogenisation technique using Digimat software », Ceram. Int., vol. 43, no 3, p. 3259-3266, 2017.

[5] W. Ogierman et G. Kokot, « Mean field homogenization in multi- scale modelling of composite materials », J. Achiev. Mater. Manuf. Eng., vol. 61, n 2, p. 343-348, 2013.

[6] L. Miccoli, U. Müller, et P. Fontana, « Mechanical behaviour of earthen materials: A comparison between earth block masonry, rammed earth and cob », Constr. Build. Mater., vol. 61, p. 327-339, 2014.

[7] N. H. Mondol, J. Jahren, K. Bjørlykke, et I. Brevik, « Elastic properties of clay minerals », Lead. Edge, vol. 27, $\mathrm{n}^{\circ}$ 6, p. 758-770, 2008.

[8] Q. Piattoni, E. Quagliarini, et S. Lenci, « Experimental analysis and modelling of the mechanical behaviour of earthen bricks », Constr. Build. Mater. Elsevier, vol. 25, p. 2072, 2011.

[9] M. J. O’Dogherty, «A review of the mechanical behaviour of straw when compressed to high densities », J. Agric. Eng. Res., vol. 44, p. 241-265, 1989.

[10] M. Tarfaoui, K. Lafdi, et A. El Moumen, « Mechanical properties of carbon nanotubes based polymer composites », Compos. Part B Eng., vol. 103, p. 113-121, oct. 2016.

[11] A. El Moumen, M. Tarfaoui, et K. Lafdi, « Computational Homogenization of Mechanical Properties for Laminate Composites Reinforced with Thin Film Made of Carbon Nanotubes », Appl. Compos. Mater., p. $1-20,2017$.

[12] A. El Moumen, T. Kanit, A. Imad, et H. E. L. Minor, « Effect of overlapping inclusions on effective elastic properties of composites », Mech. Res. Commun., vol. 53, p. 24-30, 2013.

[13] Y. Benveniste, «A new approach to the application of Mori-Tanaka's theory in composite materials », Mech. Mater., vol. 6, $\mathrm{n}^{\circ}$ 2, p. 147-157, 1987.

[14] H. G. Nguyen, S. Ortola, et E. Ghorbel, « Micromechanical modelling of the elastic behaviour of polymer mortars », Eur. J. Environ. Civ. Eng., vol. 17, n 2, p. 65-83, 2013. 